VOLUME 3 NUMBER 2 APRIL 1971
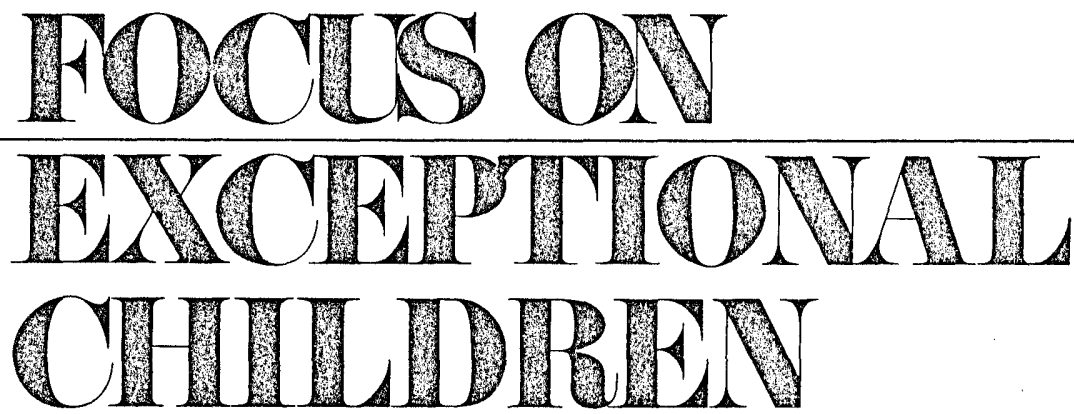

\title{
DESIGNING CURRICULUM FOR THE EDUCABLE MENTALLY RETARDED
}

\section{Warren E. Heiss and George S. Mischio ${ }^{1}$}

\section{CURRICULUM DESIGN FOR THE EDUCABLE MENTALLY RETARDED}

Curriculum development for the educable mentally retarded child is emerging from the dark ages. This emergence, although still in its infancy, is significant. An influential factor in the growing concern to provide meaningful curriculum materials for EMR children has been the results of studies to determine the efficacy of special class placement for these children.

For the most part the efficacy studies have provided ambiguous results. Kirk (1964) concluded from his review of such studies that the positive or negative values of special class placement for EMR children has not yet been demonstrated. Two recent efficacy studies warrant examination to help focus on problems that have developed from assessing special class placement.

Goldstein, Moss, and Jordan (1965) attempted to overcome deficits present in other studies by examining the interrelatedness of program, methodology, teacher competence, and subject variables. Although some of the results of this research produced equivocal findings, the study did demonstrate that a socially oriented curriculum and inductive teaching procedure produced significant results in achievement in language arts, arithmetic, and social knowledge favoring the experimental subjects. The authors concluded that these results could be attributed to a meaningful curriculum (Illinois Plan; Goldstein and Seigle, 1958) and to inductive teaching procedures. Previous efficacy studies rarely considered the influence of specified teaching plans and procedures as factors worthy of study.

The Illinois study led logically to a second investigation conducted in New Jersey (Goldstein, Mischio, and Minskoff, 1969). In this study teachers were given training in using social learning concepts as a basis for their teaching. In addition teachers were trained to correlate traditional skill areas with social learning activities. To effect this type of programming in special classes for the EMR, consultants met extensively with teachers in their classrooms to plan and evaluate curriculum efforts. The authors of this paper served as consultants to that project.

Our experience in working with teachers throughout the study indicated that our best counsel occurred when questions specifically related to problems of curriculum content were explored. Early in the project we found that our conferences with teachers were vague and often related to problems of classroom management and discipline. At best these conferences were based on random problems. Although teachers were equipped with the Illinois Plan and had been trained to create units

1. Warren Heiss is Development Coordinator and George Mischio is Skills Program Specialist at the Curriculum Research and Development Center in Mental Retardation, Yeshiva University, New York, N.Y.

(C) Love Publishing Company, 1971 
related to the social learning needs of their classes, there was still not enough of an interface to structure meaningful teacher-consultant conferences.

To create a more relevant base for conferring with teachers, several highly structured documents in arithmetic and language arts were developed by the consultants in the course of the project's duration. When these structured documents were used, relevant points of discussion arose. The documents provided criteria for examining student and teacher performance. In addition the teachers could evaluate the relevance of the materials.

Although it is difficult to present "hard" data to show this change in teacher-consultant relationship, the value of the structured curriculum materials was influential. It became apparent that the curriculum documents were the link connecting teachers with students. What had been formulated was a triadic relationship uniting teacher, student, and content. Henderson (1961) has stated this concept succinctly. "I am assuming that teaching is a triadic relation, that is, someone (a teacher) teaches something (subject matter) to someone (a student). Expressions like 'teaching subject matter' of 'teaching children' are elliptical. The statement 'I teach children, not subject matter' is absurd." Henderson's triadic relationship among child, teacher, and content is illustrated in Figure 1.

To fully understand the problems encountered in classrooms all three vertices of Henderson's triangle must be considered. Process studies have examined child variables with little regard for content or teacher variables. Teacher-pupil interaction studies have assessed the verbal

FOCUS ON EXCEPTIONAL CHILDREN is published monthly except June, July, and August as a service to those concerned with mentally retarded and emotionally disturbed children. Subscriptions rates, $\$ 9.50$ per year. Copyright 1971 Love Publishing Company. All rights reserved. Reproduction in whole or part without written permission is prohibited. Printed in the United States of America. Second class postage is paid at Denver, Colorado.

$$
\begin{gathered}
\text { Executive and Editorial Offices } \\
6635 \text { East Villanova Place } \\
\text { Denver, Colorado } 80222 \\
\text { Telephone (303) 757-2579 }
\end{gathered}
$$

\section{EDITORIAL BOARD}

Edward L. Meyen

University of Missouri

Richard J. Whelan

University of Kansas Medical Center
Frances Missing

Senior Editor
Stanley F. Love

Publisher

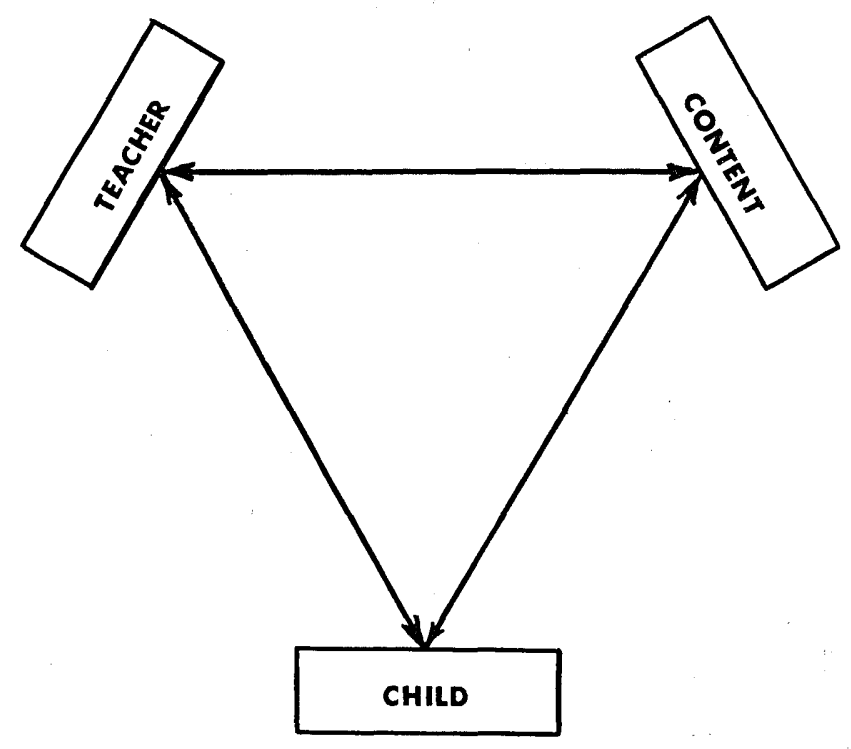

Figure 1

Triadic relationship among child, teacher and content.

and non-verbal communication between learner and tutor but have rarely considered the influence of content. If, in fact, EMR children are qualitatively different from normals, their classroom performance must be viewed in terms of curricular programming that is qualitatively different from that designed for normals. To judge the learning styles of EMR children against a curriculum background not specifically designed for their consumption will not shed light on the problem of how the EMR child learns. We must begin to ask the question, "How does the EMR child learn what?" To answer this question it is necessary to create curriculum content that at the very least possesses a face validity against which learning on the part of the EMR child can be measured. A systematic approach to the construction of curriculum for EMR children is necessary so that content can be tailored to the needs of these children.

\section{APPROACHES TO CURRICULUM DEVELOPMENT FOR THE EDUCABLE MENTALLY RETARDED}

Ever since Ingram's (1935) pioneering unit technique, efforts to design curriculum for the retarded have been diverted in several directions. Three directions can be readily identified: (1) unit approaches, (2) task analysis approaches, and (3) social learning approaches. A brief analysis of each technique will provide a perspective for 
the problems associated with effective curriculum design.

\section{Unit Approach}

The unit approach began with Ingram (1935) who suggested that units be based upon the interests of retarded children, i.e., "the Play House." These units were loosely related to arithmetic and language arts activities. Thorsell (1961) criticized topics for units as haphazard selections from elementary education or rehashed materials from other curriculums for the EMR. Thorsell proposed that "experience units" be organized to reflect the needs of the retarded and that the units be organized as either broad resource units or sub-topical teaching units. Following a social-occupational adjustment orientation, the Illinois Plan was constructed on a thematic basis of ten life function areas, e.g., Citizenship or Communication (Goldstein and Seigle, 1958). Essentially a guide, the Illinois Plan provided a framework of objectives, per theme, by which the teacher could write specific content and develop materials in social studies and correlated activities in arithmetic, language arts, and other areas. Most curriculums using the unit technique are variations of either the experience unit or life function approaches.

After examining over 250 curriculums for the EMR, Simches and Bohn (1963) pronounced most as watereddown versions of elementary school curriculums. They claim that a distinctive curriculum for the EMR could best be constructed by interdisciplinary teams of experts, since the traditional teachers curriculum committees tend to cut and paste existing curriculums which perpetuate the same static ideas. Gallagher (1967) ascribes the teacher's role as more appropriate as a field-tester since her training and experience are usually inadequate for the highly specialized theorizing and writing of curriculum content. Gallagher also cites the advantages of interdisciplinary teams for constructing curriculum.

Some of the limitations of the unit approach are the isolation of individual units, the lack of a developmental sequence of concepts and content, the regional specificity of the activities, and the lack of uniqueness of content for the problems of the retarded. The reliance on committees to write curriculum is another serious restriction since their members generally rely upon previous programs to supply the guidelines and content for new curriculum.

\section{Task Analysis Approach}

The task analysis approach is a relatively recent innova- tion. Hewett (1967) has created a hierarchy of educational tasks ranging from an "attention level" to an "achievement level" of performance. The hierarchy provides a framework for organizing the structure of the classroom materials, content, and rewards in efforts to effect meaningful transactions between teacher and child at the readiness level. Although the Hewett engineered classroom and task approach were developed through experiences with the emotionally handicapped, it appears that the system can be successfully modified for the mentally retarded (McGuirk and Maulsby, 1969).

Using a systems approach called SOME, Lazar (1969) has proposed a task analysis procedure for the retarded whereby student characteristics, program components, modalities, objectives, and evaluation items can be interrelated toward the uniqueness of the classroom situation.

At present, the task analysis approach shows promise as a powerful tool for promoting readiness, organizing content, and establishing behavioral criteria. However, Hewett's program is restricted to the readiness level and the SOME system is only a framework that is dependent upon other instruments and programs for content and consistency. The task analysis approach should be incorporated into the overall curriculum design if we are ever to construct the elusive "distinctive" curriculum for the retarded searched for by Simches and Bohn.

\section{Social Learning Approach}

The third approach, social learning, can be described as an interaction model of environmental encounters designed to develop critical thinking and independent actions on the part of the mentally retarded (Goldstein, 1969). In evaluating the social learning approach that will be described below, it is important to consider Dunn's (1968) reflections on the inadequacies of special class placement for the mildly retarded. While Dunn advocated a complete revision of the role of the special class teacher to clinical or prescriptive teacher, he also urged the formulation of a new approach to curriculum development. The first step in this approach would be one of evolving conceptual models which would be the basis for treatment programs. A taxonomy of content for such a curriculum effort would include the following topics: (1) environmental modification, (2) motor development, (3) sensory and perceptual training, (4) cognitive and language development, (5) personality development, (6) social interaction training, and (7) vocational training. While we may not agree with Dunn's clinical approach, the need for a curriculum framework to integrate these different educational goals is imperative. We shall 
show how the Social Learning Curriculum framework is one type of vehicle for realistically correlating social learning content and process abilities into an integrated educational program that reflects the unique adjustment difficulties ascribed to the retarded (Goldstein, 1964; Edgerton, 1967.

\section{THE SOCIAL LEARNING CURRICULUM}

Goldstein (1969) has identified the main pervasive characteristics of social competency as the goals of the Social Learning Curriculum (SLC). The two major goals are independent action and critical thought. The unique focus of the SLC is that of systematic presentation of increasingly more complex social-occupational concepts, facts, and behaviors required for adjustment at maturity. Furthermore, literacy and quantitative thinking abilities are developed in a parallel progression as essential problem-solving tools for unraveling the complexities of social interactions.

To reach these goals the substance of the SLC and its teaching methodology have been based on certain assumptions. Goldstein has stated these assumptions as follows:

1. A noteworthy proportion of knowledge and behavior manifest at maturity have their roots in the learning and experiences constituting the total sociopsychological growth of the individual.

2. Maladaptive and/or deficient behaviors are signs of: (a) lack of exposure to modal kinds of learning and experiences, (b) exposure to learnings and experiences that are inappropriate or antagonistic to expected behaviors, or (c) learnings and experiiences, while appropriate by ordinary standards, are either distorted or misperceived by the learner; and

3. That such learnings can be managed to the degree that the probability of lack of exposure to necessary learning, exposure to inappropriate or antagonistic learning, and the distortion or misrepresentation of learning will be reduced. In turn, this will contribute to reducing the probability of maladaption in socio-occupational endeavors at maturity.

With the goals, assumptions, and rationale for the SLC identified, the selection of a theoretical construct was essential for guidance in ordering concepts and content in a logical and developmental sequence. In order to respond to his environment, the retardate's behaviors are generally motivated by a desire to satisfy specific physical, social, and psychological needs. To the degree that the retardate has the necessary insight, skills, knowledge, or attitudes to reduce a need in a way that is harmonious with the expectations of others and rules of his surroundings, he manifests some degree of social competency.

For pedagogical purposes, the individual's needs have been reduced to fourteen inclusive areas which have been postulated as part of his motivational system (Figure 2). However, as the retardate matures, his interactions with his surroundings become more complex. In Figure 3 the expanding environment model illustrates the various social institutions which impinge on the retardate's behavior. The core of the model is the "self" which has reciprocal relationships with every environmental level. Beginning with a fairly egocentric orientation, the self should change through increased social encounters with peers and adults. The SLC is designed to capitalize on these cooperative. experiences especially as the retardate's mobility increases as he explores new environments.

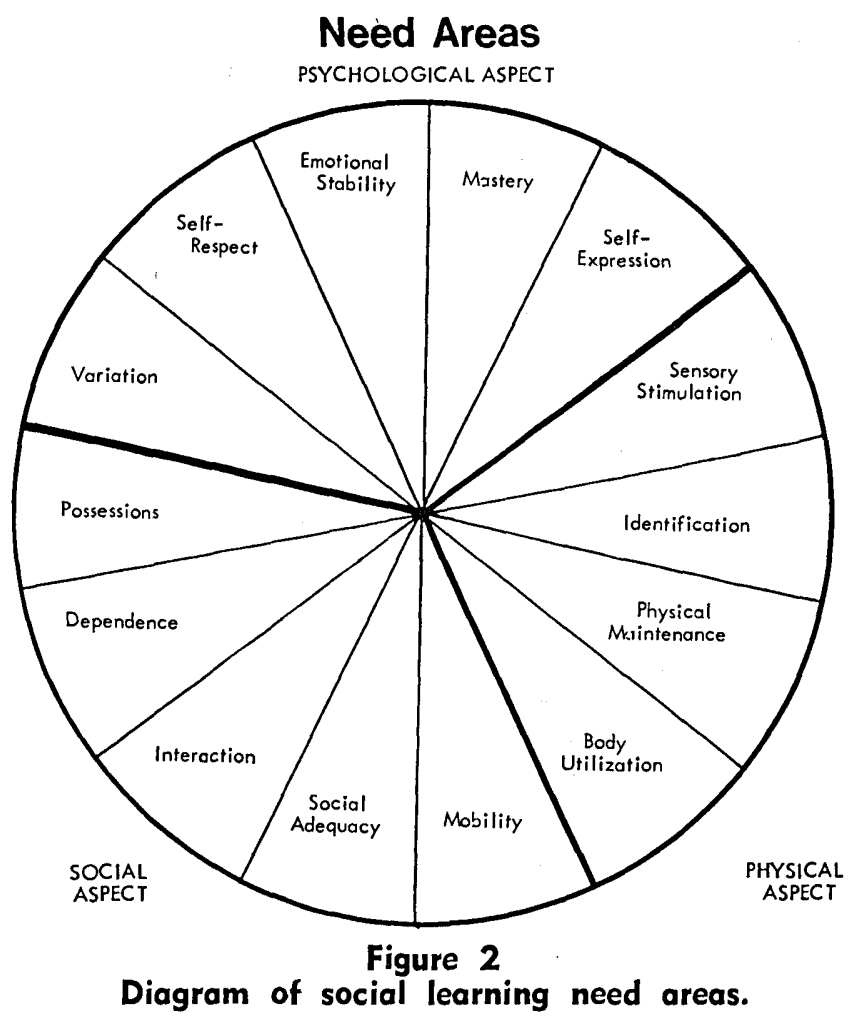

The environmental levels shown in the model (Figure 3) are arbitrarily divided for the sake of analysis, but their overlapping and interdependence are recognized. For the purposes of classroom presentation, each environmental level is emphasized and shown to be related to the self. While the "home and family" is developed as a social institution, the students soon realize that while the 


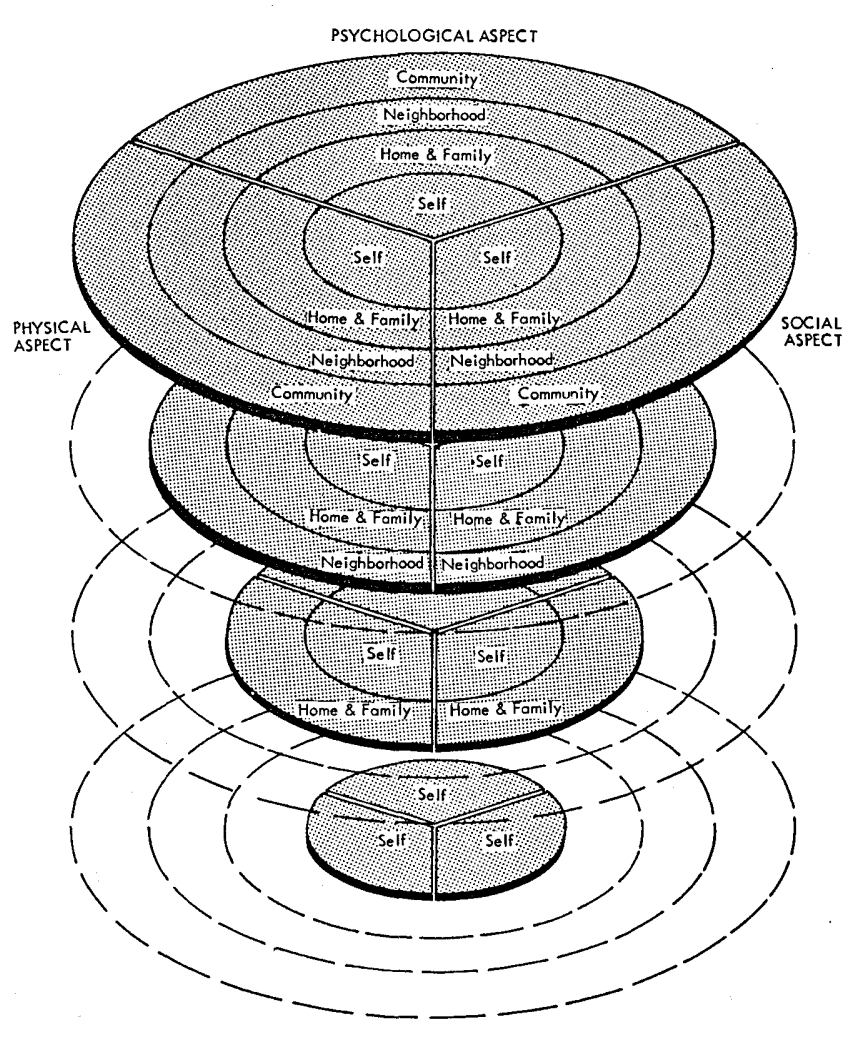

Figure 3

Model of child's expanding environment and environment components.

family has a direct influence on their behavior, their own actions can also disrupt the family constellation. For example, the child realizes the role parents play in providing nourishment can be aided if he helps with the kitchen chores, or disrupted by his refusal to set the table. Such reciprocal relationships are stressed in the SLC as a function of a sequential set of abstractions or guiding principles which unfold as the curriculum materials are used. It is this systematic exposure to more complex social experiences and the subsequent reinforcement of suitable behaviors that leads to higher level critical thought and independent behavior.

The theoretical constructs (Figure 2 and 3) supporting the SLC are essential to curriculum design because they provide benchmarks for sequential organization of concepts and content, offer cross-reference points for correlated programs, and establish a basis for organizing social interactions to solve realistic problems. The constructs also provide the curriculum developers with an opportunity to analyze the impact of conflicting social institutions on the behavior of the child.
The SLC presents a series of abstractions that has fairly universal application, e.g., "my emotions change as situations change." In the process of learning these abstractions the child is provided with an opportunity to apply them to his unique situations. Furthermore, a problemsolving strategy has been built into the content whereby the student learns to learn by using the analytical steps of labeling, detailing, inferring, predicting, and generalizing.

From a pedagogical point of view, the SLC functions as an organizer of daily activities. With the SLC as the focal point, the teacher can build activities reflecting arithmetic and language skills necessary for mature functioning. As our own efforts in curriculum building continue, the Curriculum Research and Development Center in Mental Retardation at Yeshiva University will have available correlative curriculums in other subject areas. The design of these curriculums will be discussed later in this paper.

While Goldstein (1969) offers a more detailed description of the SLC, this condensation illustrates that the SLC approach differs from the unit approach by: (1) its reliance upon a theoretical construct and subsequent research findings which will facilitate the ordering of concepts and content; (2) its specific attempt to present to the retardate social reality; and (3) its specific consideration of the learning characteristics of EMR children. The SLC differs from the task analysis approach by offering a larger developmental sequence of behaviors that are integrated into prerequisite terminal behavior patterns, and by providing a meaningful context in which tasks lead to the development of higher order tasks. It appears that task analysis can be applied to the analysis of social interactions by assessing the behavioral, cognitive, and linguistic demands of such interactions. In other words, the SLC provides a context in which tasks can be analyzed. Finally, the SLC is supported by a theoretical construct that should satisfy Dunn's requirements for a structure which can enhance training in environmental modification, personality development, social interactions, and vocational adjustment. The specific content of each teaching component of the SLC has activities, related to Dunn's requirements, appropriately built in small; manageable steps. Furthermore, the construct provides a framework for intra-lesson correlation with other subject matter areas as well as for the construction of parallel skills programs related to motor development, sensory and perceptual training, language development, and conceptual development. 


\section{A TOTAL CURRICULUM DESIGN FOR EMR CHILDREN}

From a practical point of view one of the major goals of curriculum development is to provide the classroom teacher with a comprehensive program for her students. The curriculum must attend to reaching stated goals (both behavioral and conceptual) by providing for skill growth in subject matter areas (arithmetic, language arts, etc.) and offering the teacher procedures for remediating basic learning difficulties. The SLC framework supplies a superstructure for considering application of skills learned in traditional curriculum areas to the solution of life's problems. For example, the acquisition of arithmetic skills ought to result in the solution of meaningful problems related to social behavior. Learning to read ought to result in applying reading skills to the solution of environmental problems. Perceptual training ought to have application to problem-solving and not be "perceptual training for the sake of perceptual training."

What we are proposing is simply that traditional curriculum areas carve out their content from a broad social learning context. There is no reason to believe that word analysis skills in reading cannot be learned by using words which emanate from a discussion of social learning concepts.

Programs to provide for the learning disabilities encountered in special and regular classes have concentrated on particular skills or particular skill areas. Frostig and Horne (1964) have designed materials to train children in visual perceptual skills. The Illinois Test of Psycholinguistic Abilities (Kirk and McCarthy, 1961) and programs designed to follow up ITPA diagnosis have concentrated on specific psycholinguistic skills. These approaches and other similar programs offer no overall structure for the content of remediation. Each of the programs is a piece of a larger whole called psycho-educational development.

Another problem related to the "learning disability" approach should be mentioned. The concept of psychoeducational development needs a framework in which to grow. That is, there must be an end in sight-a point where psycho-educational programming has direct application to curriculum activity areas like arithmetic and language arts. Curriculum activity areas in turn must be related to an overall structure so that the concepts and skills learned are not isolated and fragmented. The SLC model gives this structure. Curriculum activity areas and psycho-educational processes must be welded. Both need to be applied to a viewpoint about educating EMR children. The SLC presents that viewpoint.

It is, therefore, beneficial to develop a total educational program that is responsive to three interrelated dimensions. First, there should be an overall framework from which tenable educational goals can be derived. Second, attention must be given to integrating traditional skill development areas into a program that is serving the objectives of the framework. Third, child variables must be recognized as influencing learning. These interrelated dimensions serve as the basis for the model of curriculum development for EMR children. The relationship of these three dimensions is shown in Figure 4.

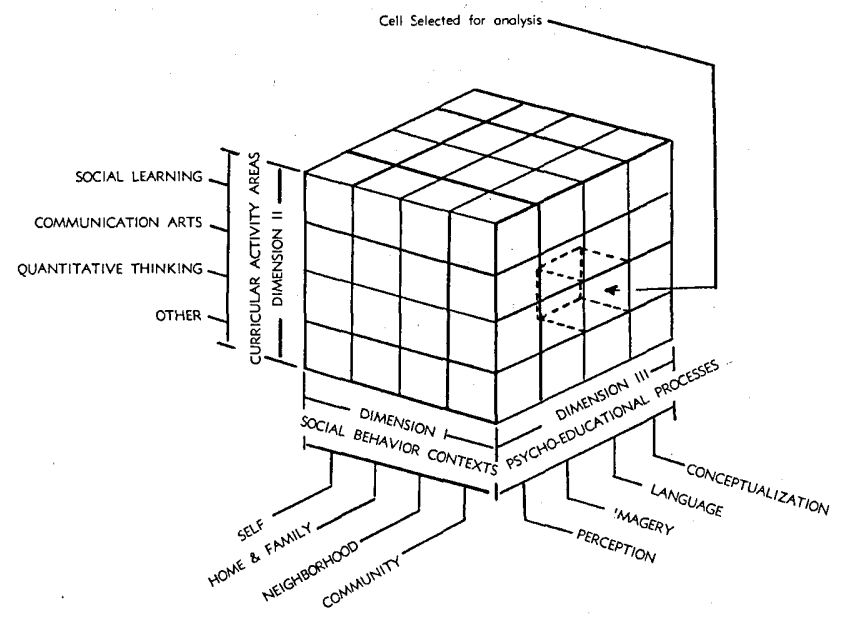

Figure 4 Model for a total curriculum design for EMR children.

The interrelationship of the three dimensions of the model can be considered in another way. The ultimate goal is to educate EMR children to perform adequately in several Social Learning Contexts (Dimension I). Performance in those contexts is a reflection of problemsolving skills attained in various Curriculum Activity Areas (Dimension II). The mastery of problem-solving skills presented in curriculum areas is a function of the acquisition or use of basic Psycho-Educational Processes (Dimension III). Practically, then, the classroom teacher can observe performance in a Social Behavior Context, decide which Curriculum Activity Area is contributing to inappropriate performance and, if necessary, analyze the Curriculum Activity Area in terms of influential Psycho-Educational Processes.

Dimension I - Social Behavior Contexts. Goldstein (1969) has provided a theoretical basis for constructing the SLC. He has emphasized the concept that the child is confronted with a series of expanding environments with which he must cope. The environments grow from the "Self" level and continue to expand through the "Home and Family" level to the "Neighborhood" level and the "Community" level. These four levels describe 
the dimension of the Social Behavior Contexts shown in the model. The levels present contexts for developing social learning concepts and behaviors.

Dimension II - Curriculum Activity Areas. Practical classroom application of curriculum mandates that teaching-learning materials reflect usual skill and concept development areas. For this reason Dimension II of the model is descriptively defined in terms of traditional curriculum labels. Curriculum activities can be ordered into categories which emphasize Social Learning, Communication Arts, Quantitative Thinking, and other identifiable subject areas.

Important in this breakdown of the Curriculum Activity Areas is the understanding that the Communication Arts, Quantitative Thinking, and other categories derive their content from the Social Learning category of curriculum activity. For instance, if the Communications Arts category results in the development of a listening skills program, Social Learning concepts and activities will serve as a context for the skill development.

Dimension III - Psycho-Educational Processes. Application of curriculum is dependent upon child-learning variables. The development of curriculum must take into account modes of learning which children apply to formulate their understanding.

Johnson and Myklebust (1967) have outlined learning as "hierarchies of experience." This means that the child moves through levels of learning behavior on a continuum from sensation through conceptualization. The levels of the hierarchy are:
1. sensation
5. inner language
2. perception
3. imagery
4. symbolization
6. receptive language
7. expressive language
8. conceptualization

From the standpoint of curriculum development and teacher application of material the eight levels can be collapsed into the following four:
1. perception
2. symbolization
3. language
4. conceptualization

Material can be prepared to capitalize on these four levels of learning. Application of the material will require diagnostic teaching. What we are suggesting is that curriculum material can be written to reflect learning styles. By using any one of the psycho-educational processes, a child could perform a desired behavior. If a child is asked to take a pint of milk from the refrigerator, he may process the task solution in several ways. The child could get the milk by using perceptual information of the size and shape of milk cartons or he could use a language process by reading the label.

Some curriculum development has taken into account levels of learning. However, the levels reflect differences in quantity such as reading achievement grade-level scores. Our contention is that curriculum materials ought to reflect qualitative differences in terms of learning styles of children.

The proposed development model, then, shows the interaction of context for learning (see Dimension I), curriculum activity areas operating as content vehicles (see Dimension II), and psycho-educational processes which influence presentation (see Dimension III).

Dimension I, Learning Contexts, follows the established expanding environment model of Social Learning. It is divided into four levels: Self, Home and Family, Neighborhood, and the Community.

Social Learning, Communication Arts, Quantitative Thinking, and other curriculum materials constitute the Curriculum Activity Area, Dimension II.

The Psycho-Educational Processes, Dimension III, are described by the terms perception, symbolization, language, and conceptualization representing levels of learning by which the development of curriculum materials must be influenced.

These dimensional interactions result in a cubical model containing sixty-four cells. Theoretically, at least, each cell of the model can be extracted from the total cube and analyzed. One of these has been isolated and is illustrated in Figure 5. Figure 5 shows the cell bound by Quantitative Thinking, Community, and Language dimensions. The Quantitative Thinking dimension has been divided into ten areas representing the main arithmetic reasoning and computation skills.

The Social Behavior Context dimension of this cell is Community, which has been subdivided into three aspects. The Physical aspect refers to information, concepts and behaviors related to the physical facilities, ecology and characteristics of the town or city, e.g., identification of stores, shopping centers, or market places in the immediate area; the residential or industrial composition of the town; or the historical landmarks within the boundaries of the community. The Social aspect would point to the types of social, educational, recreational, or vocational interactions within the community. The Psychological aspect refers to the general feeling and reactions generated by conflicts and successes in personal and vocational adjustments.

The Psycho-Educational processes reveal how different types of language can be illustrated in the model. Inner- 
language processes are used to translate the raw experiences into verbal symbols, while receptive language channels are employed to receive and comprehend via auditory or visual receptors. Finally, expressive language modes convey the internalized experiences, gained through receptive language processes, as vocal or visual forms of communication. The following example will show how the cell dimensions interrelate. The concept of punctuality is related to the Quantitative Thinking aspects of conservation of time, the mechanics of number recognition of the clock face, and knowledge of the measurement units of seconds, minutes, and hours. When these arithmetic concepts and skills are applied to the Community Social context, the physical implications of distance between home and place of employment are stressed, the social implications of being late for work, and the psychological feelings generated about the fear of being fired. The Psycho-Educational aspects of language are reinforced when the students use inner language to make the experiences of tardiness a meaningful experience, employing receptive language channels to observe and integrate the facial and vocal expressions of the boss who is annoyed by the lack of punctuality. Finally, expressive language is used to present the student's reasons for the lack of punctuality.

In summary, the proposed development model has shown that curriculum development must be based on the

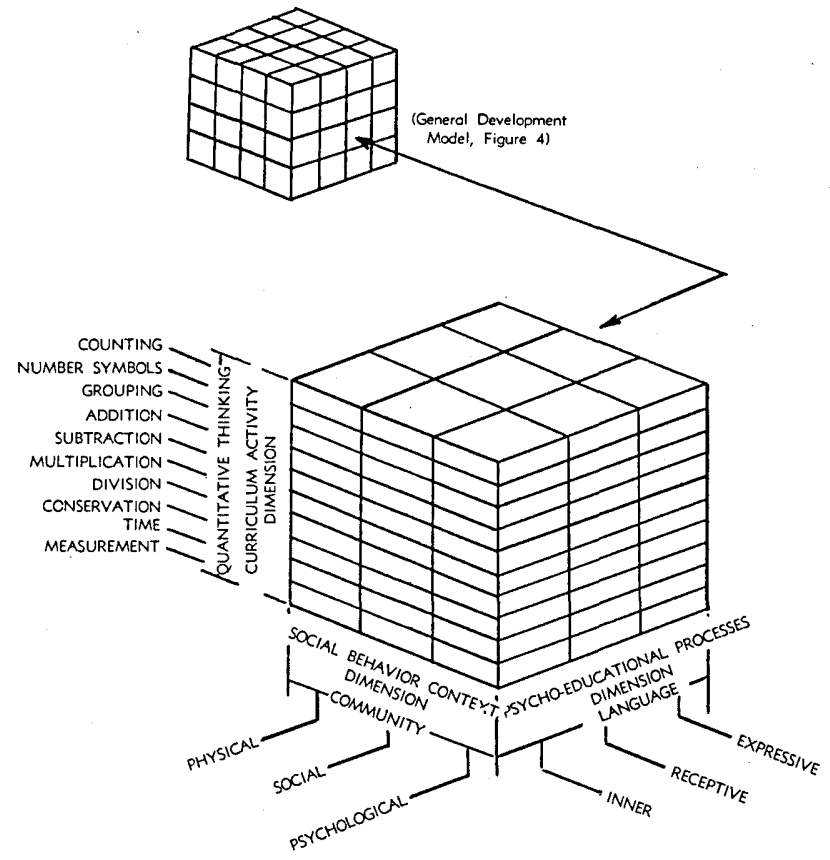

Figure 5

Illustrative cell from general curriculum development model. interrelationship of the model dimensions. Educational program development is a function of providing a framework for behavioral outcome (Social Behavior Contexts), vehicles for the presentation of subject matter problemsolving skills (Curriculum Activity Areas) and procedures for developing and correcting basic learning modes (Psycho-Educational Processes).

\section{DESCRIPTION OF SKILLS PROGRAMS} AS AN OUTGROWTH OF THE SLC

While the development model presents a theoretical consideration of the conceptual interfaces between aspects of the curriculum on the Curriculum Area-Dimension II (Figure 4), the pedagogical diagram of the total educational program for the retarded (Figure 6) illustrates the practical interrelationships between social learning, skills, and process programs.

\section{HIGHEST LEVEL. OF EDUCATIONAL FUNCTIONING}

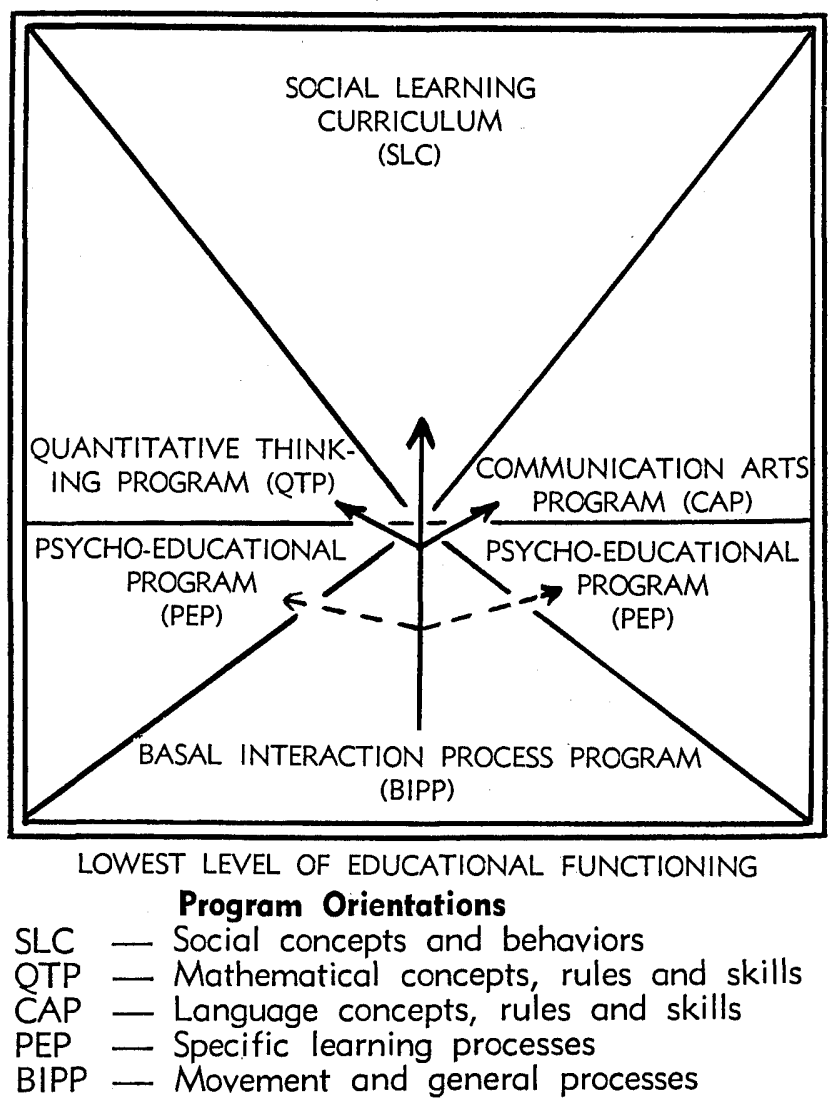

Figure 6

Schematic of the relationship of the components of a total educational program for EMR children.

From a behavioral reductionist view, the broadest concepts are taught at the SLC level, more specific concepts 
and skills developed through the QTP and CAP; and the basic readiness skills and processes are presented at the BIPP stage. If complex processing difficulties emerge during the skills programs, the teacher can shift over to the PEP for remediation of the disabilities. An example of the interrelationship of these programs can be obtained from the evaluation of an SLC field test teacher. Miss X was teaching the SLC concepts for self identification, i.e., name, sex, height, weight, etc. However, she noticed her younger students weren't motivated by drawing paper cutouts on their bodies. On closer observation, she determined that they had no understanding that the paper cutouts represented them. So she shifted to the skills program level and evaluated their arithmetic competency on size comparisons and the concepts of smaller and larger. While they could perform the mathematical computations they still did not make the necessary association. She then dropped to the readiness level and had the children construct three-dimensional cloth models of their body cutouts. Using the cloth models she was able to demonstrate concepts of laterality, midline, and body awareness which the children practiced upon themselves, transferred to the cloth model and eventually to the paper cutout. Eventually, they were able to decorate the paper cutout to correspond to their own features.

When viewed from this perspective, the position of social learning as the overall theme and the corresponding relationships of skills and process programs becomes clearer. If the teacher had not been successful at the readiness level, she would have been forced to retreat to the learning disabilities orientation of the PEP in order to remedy this process deficiency. From this perspective, it is also possible to organize the concepts and skills of each program to correspond to the lower level operations of an earlier program.

\section{RESEARCH AND CURRICULUM DEVELOPMENT}

We began this paper by pointing out the value of Henderson's triadic model for describing the nature of the teaching-learning process. Our purpose has been to illustrate the importance of content in that relationship. To conclude this paper it is valuable to reconstruct Henderson's triad to demonstrate the reciprocal relationship between curriculum development and educational research. If the triad is considered as guide for relating research to development, it then serves two purposes. First, at a molecular level Henderson shows the necessary ingredients for describing classroom events-child, teacher, and content. Second, at a molar level Henderson's paradigm can be used to describe the interaction of elements to be considered when serious efforts in curriculum develop- ment are undertaken to serve a large sample of children and teachers. The interaction of these three components can best be illustrated by offering a brief description of several research endeavors that have emanated from curriculum development efforts at the Curriculum Research and Development Center in Mental Retardation at Yeshiva University.

One problem that arises in the development of Social Learning Curriculum materials is the determination of when certain concepts can be introduced so that they can be learned with relative efficiency. Related to this problem is the difficulty of determining how these concepts are being processed by EMR children. Added to these two problems is the fact that much of the content of the SLC has an "indefiniteness" associated with it. It is difficult to define specifically the nature of the content with precision available to subject areas such as arithmetic. Mischio and DiNola (1969) have designed a piece of research which focuses on these problems. They have studied the moral judgment behavior of EMR children. The results of their study will provide information concerning: (1) some important social learning concepts and behaviors associated with moral judging, (2) the influence of CA, MA, socio-economic status, and religion on moral judgment, and (3) the levels of moral judgment that EMR children are capable of reaching. These data will be converted directly into curriculum materials for teachers and children. Once the research data has been converted to teaching materials, follow-up studies can be designed to examine how EMR children are learning moral judgment concepts.

Stolurow (1970) has proposed an investigation to examine the efficacy of computer-aided instruction (CAI) for EMR children in regular classrooms. To effectively assess the value of CAI on the learning of EMR children, Stolurow felt that it was necessary to attend to content that had relevancy to the needs of these children. Under this condition the message is at least as important as the medium. Stolurow is concerned with answering the question of how CAI influences the learning of a well-defined set of behaviors and concepts which take the form of the SLC. In this study the "teacher" in Henderson's triad becomes the computer program. An added feature of this study is the computer's ability to record the errors in learning accumulated by the children. These data can be used to revise the activity sequences created to facilitate the conceptual and behavioral objectives of the curriculum.

Certainly an important consideration in the design and development of curriculum for any group, and especially the mentally retarded, is the linguistic competence of the 
target sample. Hurley (1970) has designed a study to shed light on this problem. A pressing question for curriculum developers at our Center has been the degree to which language competency influences the stated goals of an activity or series of activities. Which linguistic competencies can be relied upon to facilitate rather complex social learnings? How does the teacher's language influence that of the child? Can the teacher be trained by a structured curriculum to use appropriate linguistic cues to aid the child? Answers to these questions are directly applicable to the writing of activities for inclusion in the LSC. Hurley is essentially providing data on all three aspects of Henderson's triad. How does the language interaction between child and teacher influence the presentation of an already defined message (SLC)?

Thus, we have tried to examine the intricacies of curriculum design for the retarded. Henderson's (1961) triadic relationship has established the parameters of the challenge facing the curriculum designer. It is our contention that a fully integrated social learning and skills program provides the contextual interface whereby researchers can assess student processing; curriculum developers can evaluate sequencing and the flow of concepts and skills; and teachers can manage learning through a systematic total educational program. Such curriculum innovations are attempts to be responsive to the most pressing adjustment and learning problems of the retarded. But the social learning approach represents only "one small step for man" since the full force of a concerted partnership of researcher, designer, and teacher must continually assess, refine, and nurture this approach within the triadic relationship of the classroom.

\section{REFERENCES}

Dunn, L. M. "Special Education for the Mildly Retarded-Is Much of It Justified." Exceptional Children, 1968, 35, 1, 5-22.

Edgerton, E. The Cloak of Competence. Los Angeles: University of California Press, 1967.

Frostig, Marianne, and Horne, D. The Frostig Program for the Development of Visual Perception. Chicago: Follett Publishing Company, 1964.

Gallagher, J. J. "New Directions in Special Education," Exceptional Children, 1967, 33, 441-447.

Goldstein, H. "Construction of a Social Learning Curriculum," Focus on Exceptional Children, 1969, 1, 2, 1-10.

Goldstein, H. "Social and Occupational Adjustment," in Stevens, H., and Heber, R. Mental Retardation. Chicago: University of Chicago Press, 1964.

Goldstein, H., Mischio, G. S., and Minskoff, Esther. A Demonstration-Research Project in Curriculum and Methods of Instruction for Elementary Level Mentally Retarded Children: Final Report. Washington, D.C.: U.S.O.E. Bureau of Education for the Handicapped, 1969.

Goldstein, H., Moss, J. W., and Jordan, Laura J. The Efficacy of Special Class Training on the Development of Mentally Retarded Children. Cooperative Research Project No. 619. Ur- bana, Illinois: University of Illinois, Institute for Research on Exceptional Children, 1965.

Goldstein, H., and Seigle, D. A Curriculum Guide for Teachers of the Educable Mentally Handicapped. Springfield, Illinois: Department of Public Instruction, 1958.

Henderson, K. B. "Uses of Subject Matter." In B. O. Smith and R. H. Ennis (Eds.), Language and Concepts in Education. Chicago: Rand McNally, 1961, pp. 43-58.

Hewett, F. M. "Educational Engineering with Emotionally Disturbed Children," Exceptional Children, 1967, 33, 7, 459-470.

Hurley, O. H. "Linguistic Competence of Mentally Retarded Children: a Research Proposal," In Goldstein, H., and others. A Proposal for a Research and Development Center in Curriculum for the Mentally Retarded. New York: Yeshiva University, 1969.

Ingram, C. Education of the Slow-Learning Child. New York: Ronald Press, 1935.

Johnson, Doris, and Myklebust, H. R. Learning Disabilities. New York: Grume and Stratton, 1967.

Kirk, S. A. "Research in Education," In H. A. Stevens and R. Heber (Eds.) Mental Retardation. Chicago: University of Chicago Press, 1964. pp. 57-99.

Kirk, S. A., and McCarthy, J. J. "The Illinois Test of Psycholinguistic Abilities: an Approach to Differential Diagnosis," American Journal of Mental Deficiency, 1961, 66, 399-412.

Lazar, A. L. "The SOME System Approach: a Paradigm for Educational Instruction and Remediation by the Special Class Teacher," Focus on Exceptional Children, 1969, 1, 7, 1-7.

McGuirk, Sister Loretta, and Maulsby, Sister Ann. "Educational Engineering Adapted for Practicum Experiences in Mental Retardation," July 1969, unpublished report of the College of Saint Rose, Albany, N. Y.

Mischio, G. S., and DiNola, A. J. “An Investigation of Piaget's Moral Judgment Stages among Mentally Retarded Children from Ages Six to Eighteen: a Research Proposal," In Goldstein, H. and others. A Proposal for a Research and Development Center in Curriculum for the Mentally Retarded. New York: Yeshiva University, 1969.

Simches, G., and Bohn, R. J. "Issues in Curriculum: Research and Responsibility," Mental Retardation, 1963, 1, 2, 84-87.

Stolurow, L. M. Computer-Aided Instruction Programs for the Educable Retarded in Regular Classes: Project CAIPER. Cambridge, Mass.: Harvard University, 1970.

Thorsell, M. "Organizing Experience Units for Educable Mentally Retarded," Exception Children, 1961, 28, 4, 177-185.

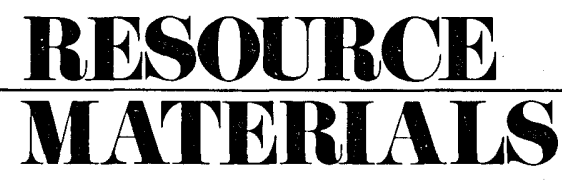

B!y Avaril Wedemeyer and Joyce Ceika

\section{GEORGE A. PFLAUM, PUBLISHER}

A new textbook directed at personality development of sixth graders, Becoming Myself, completes the upper elementary portion of an innovative series of graded texts called Dimensions of Personality.

Dimensions of Personality is a course that begins with fourth grade students; children who are developing new abilities to identify their feelings and their emotional re- 
sponses and make use of the classroom environment to foster emotional and personality growth.

The books were written for the normal child. It helps him achieve a better self image and sense of worth by introducing him to the awarness of human behavior. One book in the series, I'm Not Alone, emphasizes the child's understanding himself and how he relates to groups. It gives special attention to parent child communication. Another book, Here I Am, places greater emphasis on the child's understanding of himself. It stresses emotions, heredity, environment, growth, and self image. For further information on this series write to George A. Pflaum, Publisher, 38 West Fifth Street, Dayton, Ohio 45402 .

\section{ECONOMY COMPANY}

Oral English Learning A Second Language is a program to develop language skills in children who are having difficulty in school because of little or no command of the English language. The program consists of a pupil's book, a teacher's edition, two groups of illustrated Language Development Cards, 3 wall charts, and one pocket chart. One group of cards contain home, community, and classroom scenes to be used for concept development, sentence practice, and visual perception. Another set of cards shows specific objects to be used for practice of sounds and vocabulary building. The cards are also used in various games and activities to develop categorization and audio-visual discrimination.

The charts are used to teach colors, numbers, and weather and calendar concepts.

Further information on this program can be obtained from the Economy Company, 1901 North Walnut, Oklahoma City, Oklahoma 73125.

\section{ALERT}

The Council for Exception Children 49th Annual International Convention will be held April 18-24, 1971 at The Fountainebleau Hotel, Miami Beach, Florida.

American Association on Mental Deficiency will have its annual meeting at The Shamrock Hilton Hotel in Houston June 13-19, 1971.

The European Association for Special Education will hold an International Trade Fair and Exhibition in Norrkiping, Sweden, July 25-August 2, 1971.

\section{ISSUES}

¿ TRENDS

At the present time considerable space in the literature is being devoted to the effects of labelling, the questionable value of our traditional categorical approach to special education, and the inequities experienced in the utilization of existing procedures for assessing intelligence. If one were to select any period of time in the history of special education for exceptional children, issues of a similar nature would be found to occupy the attention of educators. It is interesting to note that while these issues are related to what takes place in the classroom, the process of curriculum development within special education has never been a central issue. Certainly tremendous investments have been made in the production of curriculum guides and in experimentation with administrative arrangement. But, for the most part, few people have addressed themselves to curriculum theory applicable to programming for exceptional children.

People are quick to criticize what is occurring in special classes. Others respond to the obvious and design research studies to confirm their suspicions. But few people have committed themselves to creating climates in which research on the systematic development of curriculum can take place. Until the emphasis shifts from a perspective of coping with the consequences of ill-designed curriculum to focus on curriculum theory, design, and implementation we will continue to perpetuate circumstances which make our program efforts vulnerable.

Curriculum research is not popular in special education. Yet it is the result of inadequately prepared curriculum which contributes to ineffective teaching. There currently is an emphasis on exploring new teacher-training models and marketing instructional modules, as well as experimenting with innovative program plans. As creative as these may be, they don't substitute for investment in the process of determining what will take place within the educational setting.

Heiss and Mischio have addressed themselves to a discussion of curriculum development. They have also referred to research relevant to the model they describe. More emphasis needs to be given to the process of curriculum development within the realm of research. The process need not be restricted to a particular area of exceptionality, but can be designed to allow for differentiation in the output according to the needs of individuals and/or groups. 


\section{\begin{tabular}{l} 
CLASSROOM \\
\hline FORUI
\end{tabular}}

Edited by Austin J. Connolly, University of Missouri

\section{PROBLEM 8}

I teach a special class of primary level EMR children. My class is the only special class located in our elementary school. Yesterday, my children came in from recess very upset. They said children from other classes were calling them names and saying they were in the "dummy class." How should I have responded in this situation?

The following letter was received in response to the above problem, and its message is worth printing verbatim. The writer is Orley Ryals, a teacher in Clarksburg, California. His contribution earns him our appreciation and a year's subscription to Focus on Exceptional Children.

An alternative to the "dummy class" stigma is converting this liability into an asset. A constructive analysis of the teacher's assets, facilities and location often reveals positive potential assets. For example, in a similar situation, there were four attributes which converted my classroom (primary EMR through Intermediate EMR) into the most popular place in school.

1. My room was equipped with an industrial arts shop. I sought out the teachers of those students who were name-callers and urged that the students of their rooms be involved in projects which needed use of nails, hammers, etc. This brought kids into my classroom (where I was the controlling force) to do project work. My older students helped the younger visitors-instant success.

2. Being in a rural area, our students were bussed to and from school by the County Department of Special Education. On field trips my class filled the bus to half capacity. By inviting classes with students of comparable chronological ages to those ages of my students, the bus was filled. More important though, my class was the host which permitted the other students privileges they were unable to get without cooperation with my students.
3. A tutorship program was developed using students from the upper grades as tutors, particularly the hyperactive students. When a student became bored or a potential problem, he/she came to my class to tutor one of my students. A marvelous tutor-student relationship developed. On the playground, woe be to the kid who name-called any of my students in the presence of one of the tutors. Also, the regular performance of these tutors improved-by teaching they were reinforcing what they had learned through earlier instruction.

4. Success of the fourth attribute depended wholly on me, the teacher. My involving myself in teacher duties and the teacher's association, I was not isolated from the faculty but an active part of it. Thus, the flexibility of my program provided the means to convert the "special" liability into a "special" asset.

Involvement, interaction, flexibility, and creativeness provide the material by which a special education teacher can use his/her assets to minimize the special class stigma. It is the teacher with enthusiasm, optimism and studentcentered goals who builds bridges upon which children walk proudly.

In the past, too many special education classes have been staffed with cowering Polly Paranoias or Joan of Arcs searching for conversions. It is a pleasure to cite a positive example of what is being done by many good teachers. Remember, it is the teacher's action that ultimately determines the acceptance of his or her children. Accept the challenge, put your best professional foot forward in their behalf.

\section{PROBLEM 10}

There are three classes for the educable mentally retarded in our elementary school. Because the special class curriculum varies from the regular program, our principal has requested that we develop our own report card. Do you have any suggestions?

All readers are invited to send their solution to Problem 10. The September 1971 issue will summarize contributions by readers. Complimentary subscriptions will be awarded each month for the best solutions. Send your response to the Editorial Offices, Focus on Exceptional Children, 6635 East Villanova Place, Denver, Colorado 80222. 